\title{
4. Social Theatre. Brief Phenomenology of a Plural, Polycentric and Participatory Performativity
}

\author{
Giulia Innocenti Malini \\ doi.org/10.3280/oa-637-4
}

\section{In the Beginning}

"Social theatre" might sound like a tautology, since all "theatre" is "social" insofar as it is the art of bodies entering into a space-time relationship. The fact that the expression social theatre has been present in Italy since the end of the 1990s and been given a new meaning (Bernardi, 1998) shows that the word theatre alone was perceived as insufficient to identify that set of participatory performance experiences, which, since the 1970s, had become increasingly widespread not only in practice, but also in national and international studies and awards, fully inscribing social theatre within the broader framework of applied performance (Thompson and Schechner, 2004; Jackson, 2007).

Social theatre is a phenomenon with many roots and different legacies. It is no doubt the child of the cultural revolution, the political and social movements, the artistic and theatrical avant-garde movements that flourished in the 1960s and 1970s (Bernardi, 2004; Schininà, 2004; Valenti, 2004; Garavaglia, 2014). Among the innovations that most impacted on its formulation, there are most certainly social animation, Animazione teatrale $e^{10}$ and the Grotowskian experience of the workshop. It is in this environment that a number of experiences took shape in the early 1980s, representing the "karst" phase of social theatre, during a period of theatrical restoration which saw the failure of a large number of those revolutionary drives. The ensuing triumph of neoliberalism and advent of globalisation led to the dissociation between art and society. Social issues became social services, political parties and movements collapsed taking with them the participation of citizens in the construction of the public good and in the fight against inequality.

It was precisely from the social problems of marginalisation, emigration, addiction, exclusion, illness and discomfort that in the 1990s the demand to put art once again at the core of society emerged, as people began to take responsibility for their own progress, their own realisation and their own care.

${ }^{10}$ For an explanation of the meaning of Animazione teatrale see the Notes on Translations on p. 7. The expression is used in this sense throughout the paper. 


\section{Areas of Application}

There are few records of the first experiences of social theatre in the 1970s and 1980s. The documentary situation improved between the end of the 1990s and the beginning of the new century with the publication of censuses and overviews (In Compagnia, 1999; Pozzi and Minoia, 1999; Conte et al., 2003) which heralded the incredible expansion of social theatre in Italy.

There are several areas in which social theatre was applied. In the first few years it was specifically used in psychiatric, prison and school contexts (Bernardi, Cuminetti and Dalla Palma, 2000; Pontremoli, 2005; Taormina and Valenti, 2013). This was followed, at the end of the 1980s, by experiences with the elderly (Innocenti Malini, 2020a), with people with disabilities (Badolato et al., 2000) and with children and young people both in local government agencies and in projects carried out by private social services. In the 1990s social theatre started being applied in situations where there were migrants (Dragone, 2000 and 2001; Balma Tivola, 2014), business people (Zanlonghi, 2005), educational and care professionals, and particularly in emergency and conflict contexts, where it gave rise to several international cooperation projects (Bernardi, Dragone and Schininà, 2002). The same years also saw the launch of training courses for social theatre operators. From the year 2000 onwards, there were several developments in different fields: in health promotion, with reference to community social theatre (Pontremoli, 2005 and 2015; Rossi Ghiglione, 2017); in artistic contexts, with the advent of the Teatro sociale d'arte ${ }^{11}$ (Porcheddu, 2017); in professional training applied to performing arts, events management, tourism; and in life skills learning in schools and in other professional settings (Bernardi and Colombo, eds., 2011 ${ }^{12}$ ).

The area of community development should be considered separately. It can be broadly divided into two cases, depending on whether the performance experiences are promoted by civil society and associations or by specific patrons with the involvement of social theatre professionals. Among the former are all the rituals, practices and performing arts which are carried out by groups of people or entire communities and which, while responding to motivations such as worship, religious or civil celebration, entertainment, personal satisfaction, political consensus, and so on, produce social capital.

\footnotetext{
${ }^{11}$ For an explanation of the meaning of Teatro sociale d'arte see the Notes on Translations on p. 7. The expression is used in this sense throughout the paper.

${ }^{12}$ A map of social theatre in Italy is offered by the magazine Catarsi. Teatri delle diversità (later to become Teatri delle diversità. Rivista europea) directed by Emilio Pozzi and then by Vito Minoia, for the Edizioni Nuove Catarsi di Cartoceto, which has published 80 issues from 1996 to the present day.
} 
These include amateur theatre, village and neighbourhood festivals and fairs, open-air games, sacred plays, civil and folklore performances, parades, palii $^{13}$ (Dalla Palma, 2001a and 2001b; Collins, 2004). On the other hand, these same experiences can sometimes be intentionally reactivated by local patrons with the help of social theatre operators and of their specific methods of intervention and with the objective of achieving specific community development objectives and strengthening social ties (Bernardi, 2015; Ferrari, 2019). In this case they are part of the second case in point and, therefore, fully entitled to feature in the field of social theatre, representing one of its widest applications, often carried out starting from projects arising in specific areas and then involving the whole community (Innocenti Malini, 2020b).

\section{Methodological Aspects}

In order to reflect on the methodological elements that so many different experiences of social theatre have in common, albeit transversally, let us analyse a primitive, emblematic case.

Bano Ferrari, a clown from the school of the Colombaioni, founded the Barabba's Clowns company in 1979 at the Salesian Centre in Arese (Milan), which at the time was what would now be called a juvenile penitentiary institute. Ferrari had been invited by its director, Luigi Melesi, to work with the young people staying at the Centre. Their collaboration led to the creation of numerous training courses on clowning techniques and shows interpreted by the Centre's students and educators (Melesi and Ferrari, 1989; Giuggioli, 2001).

As it is often the case in social theatre, the experience was born from a request for positive activation of people or groups in a problematic situation. The opportunity was provided, in this case, by the director of a penal institution. Other times it can be teachers, headmasters, operators, educators, local councillors, psychologists, doctors, who understand the resources that the theatre has to offer as a tool to improve the life context in which they work. This demand brings to the theatre unexpected economic resources, new participants, new spaces and new circumstances. In the theatre of representation, social issues are presented, if they are at all, as mere contents to be staged, while in social theatre these issues are addressed at the process level, both relational and creative, as it was the case in Barabba's work. The issues are not abstract, but concrete. They belong to the daily life of the participants. So, although the clowning gags remain the same as always, it is the process through which they are prepared that becomes an educational opportunity, initiating new relationships between the participants, based on collaboration, commitment and assumption of responsibility towards the

${ }^{13}$ Traditional horse race. 
group. The youngsters play with their bodies, make fun of each other, play rough and tumble in a protected and creative space with clear and defined boundaries, that allows them to explore new relational behaviours and face the problems they encounter every day in a functional way.

The way in which the process is conducted reveals a clear willingness to make theatre for the well-being and growth of the participants who are active players in the process. This is achieved through first-person theatricality. The performative action in its deepest sense of physical, relational and symbolic action becomes the way in which all subjects become socii $^{14}$, participating in the whole process of building or rebuilding the individual and the community. This task is no longer delegated only to the figures institutionally in charge, but shared and co-constructed by everyone according to their different roles.

Arese's experience shows a process of systemic change born and developed within the framework of an institution thanks to the mediation of social theatre practices. For the order of the Salesians it is customary to use theatre as an educational practice (Chiari and Ragazzi ed Educatori di Arese, 1995). The theatrical language used - clowning - is also traditional. Given this picture, what is the generative component that makes the Barabba's experience a situation of social development? First of all, there is the proposal of a theatrical language centred on the body, on simple physical contact, on the irreverence of characters who are halfway between circus and street acrobatics, on the almost total absence of verbalisation and, in particular, of any erudite verbal element. There is a working method that activates the direct participation of the youngsters, their taking of the floor and their assumption of responsibility. There is a process of theatrical facilitation that puts the subjects before everything else and their relationships as the foundation of the creation. In this way a type of theatricality comes to the fore that is completely new for that context, in which the process of working to learn the gags becomes the mediator and the background of the co-educative action, revealing itself in full harmony with the life experience of the young participants and a source of pleasure and satisfaction. The choice and articulation of this process is not preliminary to the intervention, but owes its transformative value to a work of co-planning that mediates between the resources and needs of all participants, be they institutional representatives, the young people attending the Centre or the social theatre operator. A mediation that, in this case, proved to be generative at the systemic level.

${ }^{14}$ From the same Latin and Italian word that features in social theatre, meaning partners, members. 


\section{Developments}

The field of psychiatry, on the other hand, offers the opportunity to observe the overall development of social theatre, not only because it was one of the first areas in which it was applied, but also because it presents several variations of social theatre employed in a number of complex and articulated experiences.

The use of theatrical practices for psychotherapeutic purposes has been commonplace in Italy since the 1960s. These activities, although carried out mainly in psychotherapeutic contexts, favoured the spread of a certain awareness of the healing resources of theatricality. They coincided, among other things, with the translation of some of Moreno's texts on psychodrama (Moreno, 1947 and 1953; Bour, 1968) and later with the edition of the works of the Lemoines (Lemoine G. and Lemoine P., 1972) and Schützenberger (Schützenberger, 1972 and 1975) which received the full endorsement of the Italian Society of Psychoanalysis.

In the same years, Franco Basaglia, psychiatrist and director of the Trieste psychiatric hospital, invited playwright and animatore teatrale Giuliano Scabia to set up a workshop with the patients and health workers (De Marinis, 1983). In the performative meaning that it took in this workshop and in the light of the Animazione teatrale principles, the theatre became a vehicle for relations and for a new idea of care that foresaw the reform of the health system based on the promotion of mental health, rather than on the containment of illness (Scabia, 1976; Pozzar, 2011). This experience is at the crossroads between Animazione teatrale and social theatre: of the former, it maintains both the political instances and the focus on the group and the assembly practices, and of the latter it possesses the dynamics of the institutional alliance and the expert and pedagogical use of artistic languages. Following these initial experiences and the enactment of the so-called Basaglia Law - no. 180 of May 1978, which made Italy the first country in the world to abolish psychiatric hospitals in favour of local health care, community services and psychotherapy -, new experiences of social theatre were initiated with the effect of supporting the reform itself. In 1983 Claudio Misculin, one of the patients-actors of the Trieste hospital, founded the Velemir Theatre, from which in 1992 the Accademia della follia (academy of madness), which continues to this day its collaboration with the mental health services of various Italian cities, was later born. In the same years Gabriele Boccaccini and the Stalker Teatro began to work at the Collegno hospital in Turin where they proposed experiences combining theatre with visual arts in order to assist former psychiatric patients on their path to social reintegration. These were years characterised by experimentation, as 
exemplified by the intervention carried out in 1985 by Bonardi, Bedoni and Fontanella at the Centro Socio Educativo di Melegnano (Milan) using Animazione teatrale techniques within the framework of psychodrama. Also emblematic was the series Follia e teatro (madness and theatre), held at the Juvarra Theatre in Turin in 1989, consisting of shows about madness run by professional companies and shows resulting from workshops carried out in mental health services where people suffering from mental health problems were both actors and authors. From the 1980s onwards, social theatre was also influenced by drama therapy, a discipline born in the Anglo-Saxon area at the end of the 1960s, devoid of a unified theorisation and characterised by different methods and practices. Drama therapy became widespread in Italy thanks to the work of a number of drama therapists including Maria Grazia Silvi Antonini and Fay Prendergast, who founded the Teatro Reginald in Turin in 1989, and Michele Cavallo, who had been conducting experiments on the applications of theatre with social and therapeutic objectives in Rome since the mid-1990s. And finally Salvo Pitruzzella, a drama therapist active in Palermo, founder in 1998 of the Scuola di Drammaterapia for the training of Italian drama therapists and the recognition of the professional title. Dating back from the late 1980s and early 1990s, is the beginning of Giulio Nava's research on the interconnections between theatre and group psychoanalysis, developed in collaboration with the study group on the social functions of theatre started by Sisto Dalla Palma at the Università Cattolica in Milan. In the meantime, at the DAMS (Drama, Art and Music Studies faculty) of the University of Bologna, Claudio Meldolesi was studying the boundary-crossings of the theatre in other disciplinary areas, such as sociology and psychology, on which he based his subsequent reflection on the theatre of social interaction (Meldolesi, 1993). The relationship between theatre and psychoanalysis, according to Meldolesi, is discontinuous but well-founded, since together they can build the world if they succeed in displacing the mechanisms of constraint that degrade the stage and the psyche to simple machines of reproduction.

The structure of the territorial services for mental health resulting from the 1978 reform generated a radical transformation of the care processes, which put great care in preventing the reintroduction of the cruelty that was once commonplace in mental institutions. For this reason the services invested heavily in creating network relations and territorial collaborations. The approach proved all the more convincing with the new century, when a clear orientation towards community psychiatry and recovery became widespread. Within this overall scenario, there are many experiences of social theatre produced in collaboration with mental health departments grouping together the hospital and territorial services dealing with mental health. These 
experiences differ in a variety of ways: in terms of objectives, methods of intervention, professionals involved, regional guidelines, local problems and actors present in the region. Taking a closer look at the situation in Lombardy, for example, there are several different models that can nonetheless be traced back, broadly speaking, to social theatre:

- psychodrama and dramatherapy groups conducted by specialised healthcare professionals for patients, funded by the different services of mental health departments;

- theatre workshops conducted by professionals external to the hospital structures (actors, drama therapists and social theatre operators) in collaboration with internal socio-sanitary operators for patients only or for mixed groups of patients and social and healthcare personnel;

- theatre workshops with groups of citizens (with and without mental health problems) proposed by theatre companies in collaboration with mental health departments, but carried out in community spaces;

- theatre activities and performance events proposed to citizens to raise their awareness of the issues of social stigma and the fight against exclusion.

There are many important experiences that testify a rich diversity. For example, the former Paolo Pini Psychiatric Hospital near Milan has been transformed into a social, cultural and artistic regional structure, thanks to the collaboration between several public and private entities. On the artistic front, Pini hosts the activities carried out by the social cooperative Olinda, in particular the festival Da vicino nessuno è normale (up close nobody is normal), in 2020 in its $24^{\text {th }}$ edition, presenting performances of new Italian groups, films, cultural meetings, events and parties, theatre workshops for children and young people. The members of the cooperative, many of whom have mental health issues, run a bar, a restaurant, a hostel, the TeatroCucina and a fresh pasta production workshop at Pini, creating a genuine recovery process ${ }^{15}$. In the same location, the mental health department of the Niguarda Hospital and the ARCA Onlus have activated the Museo d'Arte Paolo Pini, which offers art workshops conducted by professional artists in teams of psychiatrists, psychologists, nurses and art therapists with the aim of enhancing the skills of the participants ${ }^{16}$. In Magenta (province of Milan), the psychiatry operative unit, belonging to the Legnano mental health department, has started in 2002 a project called Il teatro come ponte per la comunità (that is, the theatre as a bridge for the community) to support the regional integration. It consists of two theatre workshops conducted by social

\footnotetext{
$15 \mathrm{https}: / /$ www.olinda.org/

$16 \mathrm{http}: / /$ www.mapp-arca.it/
} 
theatre operators of the local Ciridì Company, assisted by health personnel: the first attended by users of mental health services and local citizens; and a second, therapeutic one, carried out only with residents of mental health structures affected by more severe mental health issues. The activities take place in community spaces, are supported by the Municipality of Magenta and other private social patrons, and belong to the wider city project Teatrando ${ }^{17}$ (Innocenti Malini and Repossi, 2011).

In 2011, psychiatrist Fabio Lucchi, then director of the mental health department of the Spedali Civili di Brescia Hospital, where he applied the guidelines of recovery, introduced the theatre as one of the main therapeutic practices calling the group Teatro $19^{18}$ to lead the activity. Teatro 19's experience resulted from a collaboration started in 1993 with Alessandro Garzella who, with the help of a psychiatric team, had for some time been leading theatre workshops with people with mental health problems in Cascina, Tuscany, applying and developing his own approach of the game of the symptom. The Metamorfosi project was thus born, combining the artistic and cultural sphere with the social one, creating synergies between the work with fragile individuals and community development.

These are four experiences, four directions and working practices that all fit fully into the phenomenologies of social theatre. The first focuses on events, work integration and the valorisation of spaces in the perspective of a cultural transformation. The second on the discovery of artistic languages and the enhancement of personal resources. The third is strongly characterised by the alliance with the local services and community and by the desire to integrate theatrical practices with psychiatric and psychotherapeutic skills. The fourth, being a recovery tool, reinvents in the perspective of social art theatre, the relationship between care, aesthetic processes and community development. The experiential plurality of social theatre is confirmed by a comparison between Lombardy (as seen so far) and another Italian Region, EmiliaRomagna. In the latter, there is more cohesion between the activities because they are strongly supported at institutional level thanks to the Theatre and Mental Health project launched by the Region in 2008, involving the regional mental health department. In the period 2011-2016, according to data collected by the Region, 852 patients were involved in the activities. Between 2014 and 2015, twenty-four performances were produced with 135 replicas, with an average of 106 hours for each preparatory workshop and with the engagement of twenty-three regional theatre companies. The performances were attended by more than 4,000 students from schools

\footnotetext{
17 https://www.facebook.com/Il-Teatro-Come-Ponte-Per-La-Comunità-1053013261394969/

$18 \mathrm{http}: / /$ www.teatro19.com/progetto-metamorfosi/
} 
throughout the region. In 2016, a memorandum of understanding concerning the implementation of the Region's theatrical activities for mental health launched a technical research group with the participation of the Regional Councillors for Health Policies and Culture with some local and regional entities $^{19}$. The research group deals with the enhancement of the current activities with a view of reaching different audiences; and with the training, research, evaluation and fundraising to support the experiences. The processes of collaboration between the theatres and companies in the area which the Theatre and Mental Health project has set in motion have promoted the involvement of various artists, an element considered to have fundamental therapeutic effects and to mediate between services and civil society, with a view to overcoming the stigma associated with intellectual disability ${ }^{20}$. The survey carried out by the Regional Coordination of Theatre and Mental Health ${ }^{21}$ has mapped forty-eight groups promoting mental health through laboratory and performance activities. There are also several territorial networks that endorse these experiences, creating synergies and collaborations (Valli, 2018).

\section{One, None, and One Hundred-Thousand Social Theatres}

The examples we have illustrated show the variety of possible applications of social theatre. This characteristic makes it impossible to refer to a single model of intervention. Rather, we are faced with the recurrence of a range of methodologies that have, over time, proven to have a social impact at various levels, promoting the well-being of individual and collective subjects (Matricoti, 2010; Giordano et al., 2017; Rossi Ghiglione, 2017; Zappi, 2018; Giordano, Perrini and Langer, 2019; Rossi Ghiglione, Fabris and Pagliarino, 2019). The methodological and practical plurality is based on the search for performative processes that respond in a developmental and generative way to concrete, local and multiple social needs felt by different subjects in any one context. This translates into an operational flexibility which favours (and is in turn favoured by) the active participation of the co-creators of the experience and into a personal and social generativity that produces the symbolic-performative nourishment. Social theatre practices also seem to function as cultural and political mediators, particularly in relations between institutions and individuals and small groups, with specific reference to

\footnotetext{
19 Representatives of the Gian Franco Minguzzi Institution and the Art and Health Association, the Regional Health and Social Agency, the Bologna Volunteer Services Centre, the Universities of Bologna and Ferrara.

${ }^{20} \mathrm{http}: / /$ www.teatralmente.it/

21 Which includes theatre companies operating in the social-health field, third sector associations and local authorities using theatre to increase physical and mental well-being.
} 
marginal and fragile subjects. A function that produces social capital and reduces distance and possible conflict by generating opportunities for contact and agreement between different parties (Bernardi, 2017; Innocenti Malini, 2019).

In social theatre new forms of collaboration are being developed, largely unknown to professional theatre. They involve the different subjects of the contexts in which they operate, activating and renewing roles, tasks and processes. They use and implement intangible resources consisting of relationships and ties, but also of skills, traditions, stories, imaginaries, awareness and resistance. Finally, they enhance the value of extra-theatrical spaces often re-qualifying their meanings and bringing to the fore elements of beauty, aesthetics and ethics of everyday life. In short, social theatre presents itself as a polycentric practice, a network of reciprocal activations with different propulsion centres.

The facilitator/operator of Social theatre, of Teatro sociale d'arte, of Teatro sociale di comunit $\hat{a}^{22}$, of Theatre of social interaction or whatever one wants to call it, has therefore the creative task of facilitating these processes by supporting the participants in their performative and social agency.

${ }^{22}$ For an explanation of the meaning of Teatro sociale di comunità see the Notes on Translations on p. 7. The expression is used in this sense throughout the paper. 